\title{
Boquete Nahuelpan: Territorialidades en disputa en torno a la patrimonialización del ferrocarril "La Trochita"
}

\author{
Ayelen Fiori* \\ Universidad Nacional de la Patagonia San Juan Bosco (Argentina)
}

\begin{abstract}
Resumen: En los últimos años, Boquete Nahuelpan -territorio indígena ubicado al noroeste de la provincia de Chubut, Argentina-- se ha convertido en un atractivo turístico al ser incorporado al recorrido del tren histórico, conocido como la "Trochita". Este articulo examina, desde una aproximación etnográfica, la relación entre turismo, memoria y territorio a partir de preguntarse por el proceso de patrimonialización del antiguo tren y la incorporación de la Estación Nahuelpan al circuito turístico. Este artículo demuestra cómo los proyectos turísticos desarrollados en Boquete Nahuelpan omiten los procesos de memorias vinculados con el pueblo mapuche, invisibilizando determinadas prácticas indígenas en un contexto de territorialidades en disputa.
\end{abstract}

Palabras Clave: La Trochita; Patrimonio cultural; Territorio; Turismo; Mapuche.

Boquete Nahuelpan: Territorialities in dispute around the patrimonialization of the "La Trochita" railway

Abstract: In recent years, Boquete Nahuelpan - an indigenous territory located northwest of the province of Chubut, Argentina - has become a tourist attraction by being incorporated into the historic train route, known as the "Trochita". This article examined, from an ethnographic approach, the relationship between tourism, memory and territory asking about the process of patrimonialization of the old train and the incorporation of the Nahuelpan Station into the tourist circuit. This article demonstrates how tourism projects developed in Boquete Nahuelpan omit the memory processes linked to the Mapuche people, making certain indigenous practices invisible in a context of disputed territorialities.

Keywords: La Trochita; Cultural heritage; Territory; Tourism; Mapuche.

\section{Introducción}

Este artículo ${ }^{1}$ analiza las disputas de sentido, los conflictos y los procesos de negociación en torno a la patrimonialización del viejo expreso patagónico (La Trochita) y su puesta en valor turístico a mediados de los años '90. En particular, se centra en la incorporación de la Estación Nahuelpan (territorio mapuche) al recorrido turístico del ferrocarril implicando transformaciones para la zona.

La Estación Nahuelpan, se ubica en el Boquete que lleva el mismo nombre, en el noroeste de la provincia de Chubut, Patagonia argentina (ver mapa $n^{\circ} 1$ ). En este lugar, desde fines del siglo XIX, se fueron asentando numerosas familias mapuche y mapuche tehuelche; hasta que en el año 1908 dicho territorio fue reconocido por el Estado Nacional como "reserva para los indígenas de Nahuelpan" (Fiori, 2019). Pero, casi treinta años después, en el año 1937 los indígenas que habitaban la reserva fueron víctimas de un masivo y violento desalojo (Díaz, 2003).

En la actualidad, diariamente cientos de turistas llegan en el tren turístico a la Estación Nahuelpan a comprar artesanías y consumir productos artesanales. Sin embargo, en el relato oficial de "La Trochita" no se hace mención alguna a la historia de la comunidad indígena que allí vive ni al violento desalojo por el cual actualmente viven solo algunas familias en las tierras que fueron parte de la reserva indígena en un pasado no muy lejano.

Universidad Nacional de la Patagonia San Juan Bosco (Argentina); E-mail: ayelenfiori@hotmail.com 
Este artículo se propone desplegar un estudio etnográfico que analiza las políticas turísticas culturales implementadas en torno a Boquete Nahuelpan por las Direcciones de Turismo de la Municipalidad de Esquel y de la Provincia de Chubut. Mediante la combinación del análisis de entrevistas, observacionesparticipantes, folletos y páginas web oficiales, documentos y acciones implementadas en estos últimos años en la región, el trabajo procura reflexionar sobre el proceso de conformación de la Estación Nahuelpan como un "atractivo turístico" de la ciudad de Esquel en un contexto de territorialidades en conflicto.

\section{2. "Las tierras que fueron parte de la reserva"}

Boquete Nahuelpan se ubica a quince $\mathrm{km}$ de la ciudad de Esquel, en el noroeste de la provincia de Chubut, Patagonia Argentina.

\section{Mapa $\mathbf{n}^{\circ}$ 1: Ubicación de Boquete Nahuelpan, provincia de Chubut, Argentina.}

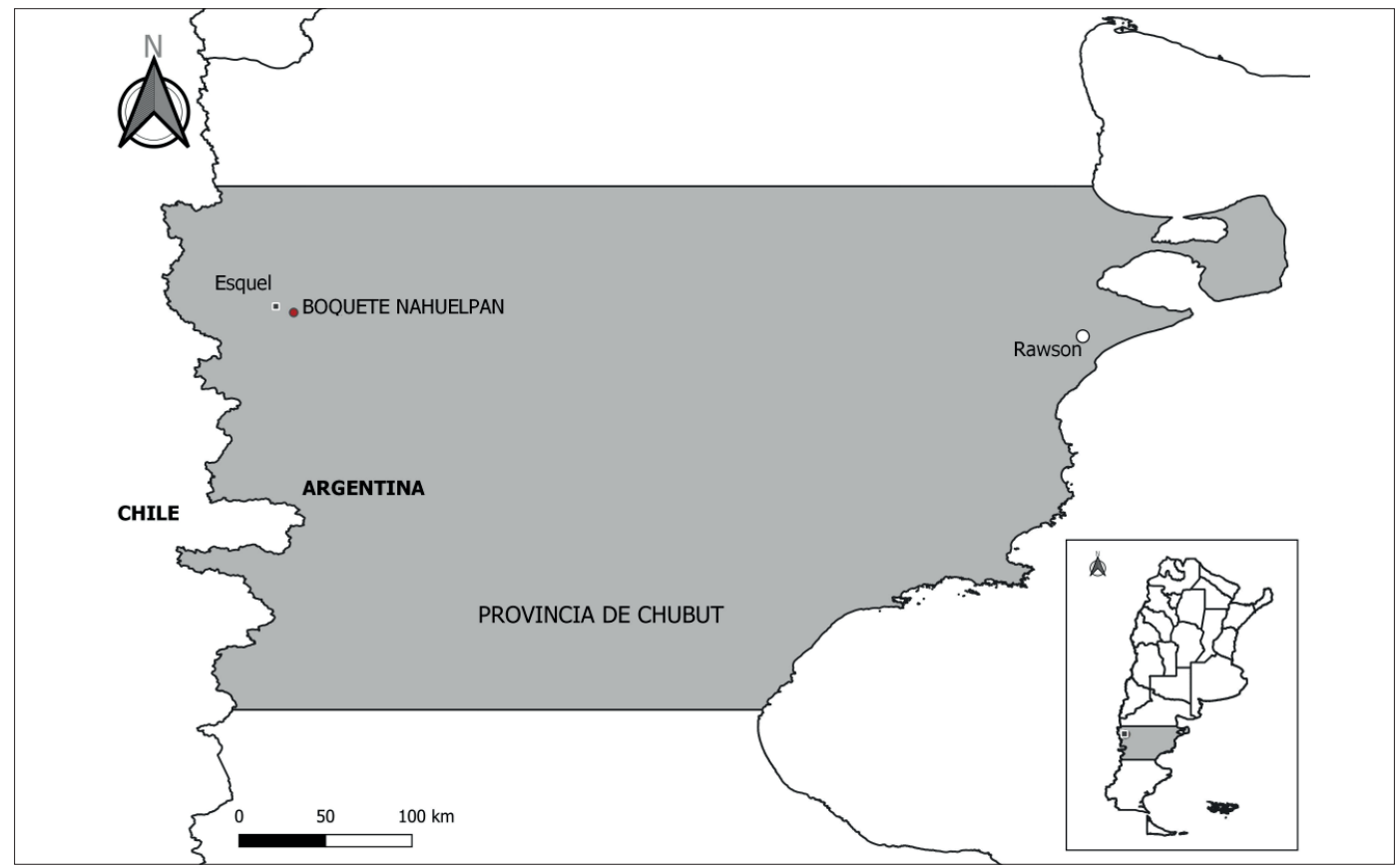

Fuente: Elaboración propia (Fiori, 2020)

Estas tierras fueron parte de la reserva indígena reconocida en el año 1908, por medio del Decreto del Presidente Figueroa Alcorta, en el cual se destinaron 19 mil hectáreas ubicadas en la parte noroeste del ensanche de la Colonia 16 de Octubre para ser ocupadas por "los indígenas de Nahuelpan"2. Este hecho se constituyó en un reconocimiento oficial del gobierno nacional de la ocupación territorial que realizaban desde hacía décadas en esas tierras. Según los relatos en torno al Boquete Nahuelpan se agruparon desde mediados de la década de 1890 varios grupos mapuche y mapuche tehuelche emparentados entre sí que desarrollaron actividades agropecuarias, ganaderas, de regadíos, venta de artesanías y comercio (Fiori, 2019)

Sin embargo, hacia mediados de la década de 1930 se instaló un discurso que puso en tela de juicio la "autenticidad de la argentinidad" de aquellos indígenas, principalmente movilizado por la ambición, de parte de la élite local, en las tierras que la reserva ocupaba (Delrio, 2005). Así se evidencia en los informes de los inspectores de tierras, los expedientes judiciales, ministeriales y policiales, donde se desataca la acusación de "carencia de civilidad" y la acusación de "extranjería" hacia los pobladores indígenas. Finalmente, en el año 1937 el presidente Agustín P. Justo mediante el decreto n 105.137 dejó 
sin efecto el decreto del Presidente Figueroa Alcorta, en el que establecía la localización de los terrenos y reservas para la "agrupación indígena de Francisco Nahuelpan"3. De esta manera, se procedió a la expulsión sistemática y violenta de todas las familias allí radicadas, las tierras que formaban parte de la reserva indígena -fueron divididas en 9 lotes de 2500 ha. -- y otorgadas a los pobladores no indígenas de las inmediaciones de la ciudad de Esquel. El desalojo de Boquete Nahuelpan no finalizó con la expulsión de los indígenas y la privatización de las tierras, sino que los grupos desalojados iniciaron un largo peregrinaje, deambulando por el territorio provincial, hasta lograr encontrar un lugar donde establecerse (Fiori, 2019).

Recién en el año 1943, e1 gobierno de facto del general Ramírez dictó el decreto 13.806 por el medio del cual se procede a caducar cuatro (de los nueve) contratos de arrendamiento. De esta manera, se ordenó la reserva de los lotes 2, 3 y 6 para ser ocupados por "los componentes de la tribu del indígena Francisco Nahuelpan", y el lote número 4 se reservó para "las necesidades del Departamento de Guerra" (Lenton, 2014: 540). Tras este hecho sólo consiguieron regresar las familias de los descendientes directos del cacique Francisco Nahuelpan. Claudia Briones y Ana Ramos (2016) analizan este hecho como una "doble desarticulación" que sufrió el Boquete Nahuelpan, primero la expulsión violenta y luego "la arbitrariedad de un permiso de retorno selectivo y a muchas menos tierras que las originariamente acordadas" (p. 207).

Con posterioridad, otras dos familias emprendieron largos procesos de "recuperación territorial" en el lote 4: por un lado, la familia Prane desde mediados de 1950 continúa resistiendo la recuperación de su territorio ancestral; y por otro lado, de manera mucho más reciente, la familia Santul- Lafquen también inició un proceso de recuperación. El resto de las personas que viven en Boquete Nahuelpan son los descendientes de las pocas familias que consiguieron volver en 1948.

\section{Memorias silenciadas}

A fines del siglo XIX las campañas militares conocidas como "Conquista del Desierto" tuvieron como objetivo la incorporación de las áreas habitadas por el pueblo Mapuche a la estructura económica del Estado nación argentino en formación. Además del exterminio y del sometimiento de miles de indígenas, el resultado fue la privatización y concentración de grandes extensiones de tierra. En cuanto al destino de los pobladores originarios, no solo sufrieron el despojo de sus territorios, sino que fueron sometidos a múltiples re-ubicaciones y desplazamientos forzosos mediante diferentes mecanismos: creación de colonias, reservas, regímenes de inclusión en el ejército y torturas en campos de concentración (Enrique Mases 2002; Delrio, 2005). Las contadas de los regresos (de campos de concentración o lugares de prisión) hacia los sitios donde podrían "vivir tranquilos" y reencontrarse con sus parientes y las "historias tristes sobre el cautiverio" (Ramos, 2010), la violencia, la pérdida de la familia aparecen recurrentemente en los relatos sobre el pasado. Según estas narrativas históricas, luego de las campañas militares comenzaron los trabajos colectivos orientados a "volver a componer" su organización familiar, política, y territorial, así como a restaurar los conocimientos de sus ancestros. Estas son las narrativas sobre cómo llegaron y dieron origen a la reserva Boquete Nahuelpan.

Sin embargo, estas memorias continúan silenciadas en la configuración del relato histórico oficial sobre estos territorios. Durante décadas, los sectores hegemónicos en nuestro país han intentado borrar, reducir o corregir aquellas marcas que dieran cuenta de la presencia indígena en la nación. La narrativa oficial de la ciudad de Esquel --como la de muchas otras en el noroeste de la provincia de Chubut-- se configuró sobre la base de la negación y/o rechazo de la alteridad indígena, construyendo el relato como una "historia de poblamientos" de familias no indígenas que se establecieron en las inmediaciones de la ciudad.

La primera aproximación historiográfica sobre el origen del poblamiento en Esquel fue durante largos años la Edición $25^{\circ}$ Aniversario del Diario Esquel editada en 1950, la cual fue utilizada como un "relato oficializado" en escuelas y medios de comunicación ${ }^{4}$. Dicha obra planteaba que el pueblo de Esquel había nacido alrededor de la instalación del telégrafo el 25 de febrero de 1906, suceso considerado "fundacional". Esta narrativa no incluye en su relato que gran parte de los primeros pobladores de la zona de Esquel fueron indígenas que se establecieron luego de las campañas militares en la zona, como tampoco realizan mención a la Reserva indígena la cual estaba conformada desde antes de la fundación de la ciudad y a tan solo $15 \mathrm{~km}$ de distancia.

De esta manera, mientras el relato oficial de Esquel celebra el poblamiento de la zona recién a principios de siglo XX con la llegada de los pioneros junto con el telégrafo, omite que en esos mismos 
años muchas personas mapuche-tehuelche continuaban deambulando por las tierras patagónicas en búsqueda de un lugar donde asentarse después de haber sufrido la dispersión o la muerte de sus familiares y conocidos, la desestructuración de sus grupos y la expropiación de sus tierras luego de las campañas militares de fines del siglo XIX (Delrio, 2005; Ramos, 2010).

Recién en el año 1993, el historiador local Marcelo Troiano, publicó "Y nació Esquel" (2003) libro en por el cual comenzó a rebatirse la "teoría del telégrafo" como fundacional y visibilizarse a los primeros ocupantes indígenas que vivían en las tierras sin demarcar a través del análisis de expedientes históricos y del archivo del Registro Civil. En años posteriores, esta investigación fue retomada por otros investigadores como Jorge Oriola (2014) y Marcos Sourroullie (2019) quienes plantean que desde fines del siglo XIX en la zona se radicaron un conjunto de familias mapuche tehuelche anudando en esta zona una serie de trayectorias marcadas por el destierro y la persecución estatal de las campañas militares. Estos datos históricos se corroboran en las memorias de las familias indígenas quienes recuerdan los relatos de sus abuelos sobre el momento en que se instalaron en la zona. Como explica la nieta de uno de los antiguos pobladores de Boquete Nahuelpan:

"Mi abuelo Eduardo Prane y Nahuelpan era lanceros de Sayhueque. El cae en cautiverio con los Choiman, Basilio, Epulef, Nahuelquir, Napaiman. Salen del cautiverio con la condición de que se establezcan en este territorio (...) Acá en este lugar se iban encontrando con los familiares después de la campaña del desierto. Así van llegando y se van estableciendo. Cuando habitan toda esta zona, había 9 líderes indígenas, podríamos decir, que eran 9 logkos (caciques). Pero no tenían autonomía como ser 9 comunidades separadas, sino que estaban emparentados entre sí” (A.P. Conversación personal, 2018)

En este fragmento, la entrevistada recuerda el derrotero emprendido por su abuelo junto con otros indígenas, hasta lograr instalarse en la zona de Nahuelpan donde "se iban encontrando con los familiares después de la campaña del desierto".

Pese a los grandes aportes de estas investigaciones locales, la narrativa oficial continúa en el presente (des)conociendo la previa ocupación indígena en la zona de Boquete Nahuelpan, omitiéndolos como "primeros pobladores" y silenciando la antigüedad diferencial de los pobladores mapuche y de los denominados pioneros, o las prácticas violentas que estos últimos llevaron a cabo para acceder a la propiedad de la tierra, sino que también operan como legitimadores de formas de clasificación y solapamiento de colectivos sociales, especialmente de mapuche, establecidas a lo largo del tiempo en el noroeste de Chubut, que han justificado políticas territoriales excluyentes y despojos hacia este pueblo.

En esta línea, es preciso recuperar los aportes de MichelRolph Trouillot (1995) quien para analizar la historia de la revolución haitiana, describió dos mecanismos mediante los cuales operan las narrativas históricas dominantes, desplegando silencios y reprimiendo lo impensable para acomodarlo al terreno de "lo aceptado". Me centraré entonces en identificar las "estrategias de borramiento" y las "estrategias de banalización" utilizadas por el autor, con el fin de entender cómo las narrativas históricas de la ciudad de Esquel demarcan una otredad interna, banalizando e silenciando a ciertos sujetos y eventos, subsumiendo las voces múltiples en una sola narrativa.

Las estrategias de borramiento, operan en el plano del contenido, invisibilizando y delimitando lo que se dice o lo que no se dice. A continuación menciono algunas de las ausencias significativas en la producción de sentidos locales. En primer lugar, no se especifica cuándo llegaron las familias mapuche a la zona, implicitando un arribo similar (o posterior) en fechas al de los pioneros. En segundo lugar, se silencian las causas y las relaciones locales que explicarían las causas del desalojo de 1937 y por qué estas familias perdieron su territorio, reduciendo los lotes que ocupaban a lo largo de los años. En tercer lugar, como analizaremos más adelante, el proceso de turistificación de los últimos años legitima el discurso dominante ocultando por qué hay familias mapuche allí y borrando los relatos de las familias sobre su historia y su presente en el territorio.

Pero también existen otros mecanismos de silenciamiento, que tienen un carácter más indirecto, como las "estrategias de banalización", que al banalizar lo sucedido, también lo ocultan o niegan. Ante la ausencia de ciertas informaciones sobre los procesos históricos desiguales de distribución territorial, se producen relatos ahistóricos y reduccionistas tales como la creencia de que los pobladores mapuche no "progresaron" a causa de sus incompetencias y que por eso perdieron sus tierras. Y es que, parafraseando a Huberman (2014): "no basta, pues, con que los pueblos sean expuestos en general: es preciso además preguntarse en cada caso si la forma de esa) exposición -encuadre, montaje, ritmo, narración, etcéteralos encierra (es decir, los aliena y, a fin de cuentas, los expone a desaparecer) o bien los desenclaustra (los libera al exponerlos a comparecer, y los gratifica así con un poder propio de aparición)" (p. 150) 


\section{La historia del "viejo tren a vapor" devenido en patrimonio histórico}

Otro hito destacado por la narrativa histórica de la ciudad de Esquel es la llegada del ferrocarril "La Trochita" en el año 1945. Este tren de trocha mínima o "económica" representó un motivo de celebración ya que implicaba "el rompimiento del aislamiento regional" y abría el camino para poder "comerciar con el resto del país los productos locales como la lana y cueros de la zona" (Oriola, 2014). Como lo relataba el diario Esquel en su edición especial del año 1950:

"El 25 de Mayo de 1945, cuando la Patria se viste de gala para festejar el magno acontecimiento de 1810, nuestra localidad agregó otro motivo de júbilo con la inauguración del ferrocarril en el tramo El Maitén-Esquel. La locomotora penetró engalanada con banderas argentinas, llevando en sus estridentes pitadas, el anuncio de una era de mayor progreso.” (Edición Especial Diario Esquel, 1950)

El historiador Jorge Oriola (2004) plantea la relación existente entre la extensión de los ramales de la Trochita y los intereses de comercialización de productos laneros de parte de los terratenientes de la zona, como es el caso de la Compañía Argentina de Tierras del Sud, actualmente propiedad de Benetton (Minieri, 2006). De acuerdo con este autor, el recorrido del tren a vapor fue readaptado en función de la Compañía de Tierras del Sud, ya que sus vías terminaron cruzando los campos de la Compañía, modificando la planificación prevista para ligar distintas localidades de la región, el desarrollo territorial y productivo de las localidades (Oriola 2004). Paradójicamente, el autor señala que con la llegada del ferrocarril se accedió de manera más rápida y económica a los productos del norte, lo que perjudicó notablemente a los pequeños productores regionales.

Sin embargo, en el año 1992 el gobierno del Presidente Carlos Menem procedió al cierre del ramal, como tantos otros cierres de ramales y privatizaciones que promovió en esa década el gobierno nacional con la desarticulación de las redes de ferrocarriles de todo el país. Unos años después, los gobiernos provinciales (Rio Negro y Chubut) deciden hacerse cargo de la operación de La Trochita, convirtiéndolo en un ícono turístico de la zona (Sitio Oficial de la Trochita). Como parte de este proceso, La Trochita fue activada patrimonialmente a partir del año 1998 cuando se la declara Patrimonio Histórico Nacional por decreto PEN No 349/99. Actualmente, el tren realiza tres clases de recorridos turísticos: Uno desde El Maitén hasta Desvío Thomae, otro Esquel- Nahuelpan; y el tercer recorrido Esquel- El Maitén.

De esta manera, el tren la Trochita es patrimonio histórico y cultural de la región, que recibe admiración y visitas de los turistas que visitan la localidad de Esquel. El viaje en el "viejo expreso" se convirtió en un "servicio exótico" que ofrece a sus visitantes "un viaje hacia el pasado". Como se observa en un fragmento del relato extraído de la página web de la Dirección de Turismo de la Municipalidad de Esquel:

"La Trochita nos da la oportunidad de conocer un bellísimo e imponente paisaje, viajando de la misma forma que desde hace setenta años. Sus pequeños vagones y su particular trocha angosta lo hacen único en el mundo y convierten el trayecto en una verdadera aventura. Recorre 18 kilómetros hasta la estación Nahuel Pan, el lugar de residencia de una comunidad Mapuche Tehuelche. Allí, mientras el tren realiza las maniobras para el regreso, se puede visitar el Museo Nahuel Pan que preserva el patrimonio de los pueblos originarios y la Casa de las Artesanas, en donde se exponen piezas de plata, madera y textiles todas hechas por la población rural de la zona que concretan en este sitio una venta directa". (Página de Turismo Municipalidad de Esquel)

De esta manera, el mayor atractivo que ofrece el viaje es el "viajar de la misma forma que desde hace setenta años". La visita a la Estación Nahuelpan es sólo un valor agregado, donde pueden "comprar artesanías y comidas típicas" mientras el tren "realiza las maniobras de regreso" (Sitio Oficial de la Trochita).

Gilberto Gimenez (2002) plantea que el patrimonio está ligado estrechamente a la memoria colectiva y por ende a la construcción de la identidad de un grupo. En efecto, el autor señala respecto a la relación entre memoria e identidad:

"el proceso de patrimonialización responde en primer término a una "demanda social de "memoria" en búsqueda de los orígenes y de la continuidad en el tiempo, lo que conduce a un gigantesco esfuerzo de inventario, de conservación y de valorización de vestigios, reliquias, monumentos y expresiones culturales del pasado. Y como la memoria es generadora y nutriente de identidad, responde también a la necesidad de crear o mantener una identidad colectiva mediante la escenificación del pasado en el presente" (Gimenez: 2002: 3) 
La patrimonialización actúa como "retorno simbólico al pasado". Lo que se ha definido históricamente como patrimonio, generalmente es presentado como universal y homogéneo para una sociedad, sin embargo, puede no ser compartido por diferentes sectores de esa sociedad. El tren- museo es el espacio donde se selecciona, conserva, exhibe y conmemora el patrimonio, donde se articulan y descartan determinadas expresiones simbólicas, se ordena la continuidad entre pasado y presente y se establece lo propio y lo ajeno. El viejo tren se vuelve una puesta en escena del patrimonio construido como significativo de una cultura. De esta manera, si consideramos los aportes de García Canclini (1989) sobre la definición de patrimonio, podemos pensar que el patrimonio no incluye solamente los monumentos o bienes del pasado, sino también las manifestaciones actuales visibles o invisibles. El autor señala que al analizar lo que se considera patrimonio, tenemos que atender a las desigualdades que surgen en su formación y apropiación, que lo visibilizan como un espacio de lucha material y simbólica.

En este sentido, es necesario pensar el patrimonio atravesado por el conflicto, la tensión y las negociaciones entre diferentes sectores de la sociedad. En el caso de Esquel, hay una clara tensión y conflicto respecto de la patrimonialización del antiguo trencito --incluyendo su paseo a la Estación Nahuelpan-las memorias en disputa y la conformación de la identidad "esquelense", lo que manifiesta una clara disputa por el territorio y la memoria.

La singularidad del lugar aparece como una pieza clave del capital cultural local a ser preservado en forma de patrimonio. Como ha mostrado Christopher Tilley (2006) identidad, paisaje y patrimonio están muy estrechamente relacionados. Los procesos de patrimonialización tienen por finalidad "la preservación de una identidad romantizada, la búsqueda de la pureza de grupos étnicos y la continuidad frente al cambio" (Tilley, 2006: 14). Tilley (2006:15) plantea que tipo de paisaje que se produce está ligado a las políticas de identidad y a las ideas sobre quiénes son incluidos y a quienes se excluye.

\section{La conformación de la Estación Nahuelpan como atractivo turístico}

Las imágenes, representaciones e ideas que se incorporan en los materiales de promoción turística, funcionan como "soportes" del imaginario turístico. En este trabajo, intentamos interpretar cómo se configura el imaginario turístico sobre Nahuelpan, analizando qué tipos de imágenes producen las páginas web de la Secretaría de Turismo de la ciudad de Esquel y del Viejo Expreso Patagónico, así como los relatos producidos por funcionarios públicos en entrevistas personales o para diarios locales.

La patrimonialización de la Trochita y el posterior desarrollo de la actividad turística reforzó viejos borramientos y banalizaciones (Trouillot, 1995), y recreó nuevos. El análisis del caso balinés de Leslie Dwyer (2009) menciona que el turismo va construyendo ciertas imágenes de su población y de su historia para fomentar su "atractivo" y volverse así comercializable. En este sentido, el turismo construye representaciones que se instalan y sostienen en los espacios donde se imponen, ya que depende de las mismas que la localidad siga siendo un espacio turístico. A continuación analizamos un fragmento donde promocionan los dos espacios en los que se "preserva el patrimonio de los pueblos originarios". Uno de ellos es el Museo de Culturas Originarias, que se ubica a 15 kilómetros de Esquel y es parte del trayecto del Viejo Expreso Patagónico. Como se menciona en la página web:

"Allí se puede tener un acercamiento a la comunidad Tehuelche - Mapuche y al entendimiento de su cosmovisión mediante los relatos actuales de sus descendientes. Trabajos de arte textil, instrumentos, alfarería y otros elementos de estas poblaciones junto con su historia se exponen en el lugar. Quienes trabajan y atienden al visitante son descendientes de mapuches y tehuelches. En la Patagonia, la gran mayoría viven en áreas rurales desfavorables para la producción agrícola y alejados de los centros urbanos, por lo que es importante que puedan mantener viva su cultura y sus costumbres" (Página de turismo Municipalidad de Esquel).

El otro espacio que es promovido por la Dirección de turismo es la Casa de las Artesanas, donde se pueden obtener "auténticas piezas patagónicas realizadas por artesanas que encuentran en este trabajo una alternativa para "mantener su modo de vida", ya que en ese lugar las mujeres comercializan sus artesanías textiles. Y concluye diciendo "Para conocer la Casa de las Artesanas y el Museo de Culturas Originarias viajando en el Viejo Expreso Patagónico de la misma forma en que se hacía cuando el tren se puso en marcha en $1945 "$.

Ambos espacios, el Museo de las culturas originarias y la Casa de las Artesanas, son señalados como espacios específicos donde se podrá "encontrar" vestigios o manifestaciones culturales de un pasado 
aborigen, a su vez, se promueve la visita a las comunidades para "verlos conservando sus costumbres" ${ }^{6}$. De esta manera, el relato va construyendo para la audiencia del turismo una representación de Nahuelpan ahistórica y desterritorializada. Las culturas originarias son "convertidas en un escaso recurso y un bien estético" el cual se materializa en expresiones como "el camaruco (ceremonia mapuche), las artesanías de tejido, los instrumentos musicales, el quillango, los abalorios, la comida, los juegos infantiles y las leyendas" (Ramos y Delrio: 71).

La visita a estos espacios es nombrada por la guía como parte del itinerario que pueden realizar al llegar a la Estación Nahuelpan. A continuación reconstruimos una parte del relato de la guía:

"cuando lleguemos a la Estación Nahuelpan van a ver que las casas están hechas de durmientes. Van a poder visitar la casa de artesanas y está el museo. Después hay gente que vende productos la mayoría es gente que viene desde Esquel (...) Se pueden sacar fotos y el tiempo de regreso lo marca el silbato del tren. Muchas gracias" (Registro de campo, relato de guía del tren, 2017)

Como se observa en este fragmento, la única mención que se hace de los habitantes originarios de la zona es relacionada a la venta de artesanías en la que aclara que "la mayoría es gente de Esquel", restando de alguna manera importancia a las familias que aún viven allí. En este sentido, recuperamos a Llorenç Prats (1997) quien introduce el análisis del patrimonio como un bien de consumo, y de esta manera invita a pensar la nueva dimensión que han adquirido las activaciones patrimoniales en la actualidad, la mercantilización: "han entrado abiertamente en el mercado y han pasado a evaluarse en términos de consumo (visitantes fundamentalmente, pero también merchandising y publicidad mediática), actuando éste, el consumo, como medidor tanto de la eficacia política como de la contribución al desarrollo o consolidación del mercado lúdico-turístico-cultural" (Prats: 1997: 4)

De este modo, "lo indígena" es incorporado al relato oficial despojado de sus condiciones históricas, culturales y geográficas. Esto implica una "visibilización de lo indígena" (Crespo, 2017) centrada exclusivamente en el marketing oficial y su "puesta en valor" y/o "patrimonialización" como producto turístico o como parte del "patrimonio local".

\section{Disputando memorias y "sentidos de lugar"}

El territorio, como espacio-lugar social, ha sido entendido de diferentes maneras. En este trabajo se retomarán dos perspectivas que permiten comprender el proceso de configuración del territorio. Una de estas perspectivas piensa el espacio como una representación de las relaciones de poder, y la arena en la cual esas relaciones sociales se reproducen (Haesbaert, 2013). Por otro lado, el espacio puede ser pensado como un cruzamiento de trayectorias, un espacio practicado e intervenido por quienes lo practican, transitan, ocupan o abandonan (Ingold, 2011). El concepto de "habitar" propuesto por el autor es útil para describir la importancia de la manera en que las personas aprehendemos los espacios que habitamos y los sentidos que construimos en torno a esos territorios.

Estas perspectivas permiten pensar las materialidades y representaciones del espacio lugar como resultado de estructuras de poder desiguales. Pero también, invitan a pensar dentro suyo el lugar que ocupan las trayectorias sociales de las personas. En este sentido, la territorialidad será pensada tanto como una arena de disputas, en la que se conjugan memorias, sentidos de pertenencias, arraigos, afectos y proyectos. A través del tiempo, en el espacio se inscriben las costumbres, las memorias, prácticas y formas de organización social, que van constituyendo un "espacio histórico propio" para las personas que allí habitan.

Como se dijo anteriormente, las familias de Boquete Nahuelpan han vivido múltiples despojos a lo largo de su historia, desde las campañas militares de fines del siglo XIX, la privatización de las tierras tras el desalojo de 1937 y más recientemente, el desarrollo turístico de la Trochita - impulsado por empresas privadas y fondos de la Provincia de Chubut-ha impulsado transformaciones en el territorio que actualmente es parte de la comunidad. Según me explicaron en la Oficina de turismo de Esquel alrededor de treinta mil personas viajan en el tren con destino a la estación Nahuelpan en el año, de lo cual la comunidad no recibe ningún tipo de beneficio. Un poblador mapuche de Boquete Nahuelpan reflexiona sobre esto último:

"Nunca La Trochita le dejó una regalía a la comunidad, aun cuando está pisando su tierra continuamente." (B. L. C, Conversación personal, Esquel, 2018) 
De esta manera, diferentes personas que viven actualmente en Boquete Nahuelpan denuncian que ellos no reciben ganancias del proyecto turístico impulsado por el Estado Provincial y privados. En este sentido, otro poblador denuncia el relato producido por las guías del tren por ser ahistórico y casi nulo habilitando múltiples representaciones sobre ellos:

"la comunidad no es parte de las ganancias. Llega el tren. La gente mira. En el relato del viaje no se habla de la comunidad. Muy poco se nombra a la comunidad. El turista piensa que va llegar a una comunidad con taparrabo" (Entrevista a miembro del Proyecto Tokom Topayiñ, Esquel, 2017)

Las dinámicas socioterritoriales que se producen en torno al desarrollo del turismo, producen y re-producen desigualdades sociales que son materializadas en el territorio, de esta manera los territorios se convierten en campos de fuerza. Como parte de las transformaciones territoriales que acarrea el turismo se desarrollan creaciones y recreaciones de territorialidades como también resistencias que buscan ir más allá de lo instituido.

Entendiendo que el territorio también es movimiento, puesto que los sujetos se constituyen en trayectorias diversas a través de sus igualmente heterogéneos modos de circular en él (Grossberg, 1992). Específicamente, Grossberg (1992) define trayectoria como "movilidad estructurada", ofreciendo una metáfora cartográfica que articula estructura y agencia en la construcción de los distintos espacios transitados como moradas de apego y/o como instalaciones estratégicas para la acción conjunta.

Entendiendo el desalojo como un evento devastador, no sólo se expulsó a las familias del territorio y se desarticuló la reserva indígena; sino que también, inauguró otra lógica económica en esas tierras. Las pocas tierras que fueron restituidas --a los descendientes directos de quien fuera el cacique Francisco Nahuelpan-- son definidas por los actuales pobladores como "desérticas" y "poco productivas". En una entrevista realizada a un miembro de la comunidad hace referencia a la situación en la que viven los pobladores que quedaron en el Boquete Nahuelpan:

"Nos dieron las partes más desérticas, no las mejores tierras. Hoy cada día se nota más, la desertificación, que cada día podés tener menos animales y la sequía cada vez se nota más. No es lo mismo hoy que hace doce años atrás" (F. H. Entrevista personal, 2017)

De esta manera, gran parte de los grupos mapuche tehuelche se insertaron en el mercado como abastecedores de fuerza de trabajo requerida por unidades integradas en distintos circuitos económicos de la región, ya sea migrando a la ciudad para realizar trabajo doméstico o en la construcción; trabajos golondrinas como la esquila o en los campos privados como puesteros o peones. De este modo lo relata un poblador:

"La mayoría de la gente de la comunidad tiene que trabajar afuera. En Esquel y algunos en otros campos como peones. No les queda otra que trabajar de peones con otros estancieros (...) Con la crianza de animales no llegas. Igual, así como nosotros todos los miembros de la comunidad tienen animales, 80 o 100 ovejas, algunas familias todavía tenemos chivas. Porque las chivas necesitan más extensiones de tierra. Se ha achicado el número de las familias, muchos se van a la ciudad a trabajar y ya no pueden volver. Se les complica volver todos los días para hacerse cargo de los animales (...) Y se terminan yendo" (F. H. Entrevista personal, 2017)

Como parte de esta situación, un entrevistado retoma un viejo dicho mapuche "la familia crece, pero la tierra no". Sin embargo, en los últimos años la conversión de la estación Nahuelpan como "atractivo turístico de la zona" ha reestructurado nuevamente el espacio, y ha permitido que las familias que viven actualmente en Boquete Nahuelpan generaran nuevas estrategias como es el caso del proyecto de Turismo rural comunitario.

Siguiendo a Prats y Santana (2011), en los últimos años se suscitó la aparición de un turista que más que buscar algo, está interesado por vivir experiencias vinculadas con la "cultura local". En este marco, la articulación entre territorio, cultura y turismo comenzó a observarse desde diversos ángulos. Por un lado, la diversidad cultural y el patrimonio se consideraron como recursos plausibles de atraer turismo. Por otro, el turismo se percibió como la posibilidad de acceder y difundir conocimientos, prácticas, experiencias, producciones culturales a toda la sociedad; y finalmente, de generar recursos económicos para la preservación de los mismos. 
En este contexto, en Boquete Nahuelpan desde el año 2013, un grupo de pobladores interesados en el desarrollo turístico comunitario comenzaron a reunirse con el objetivo de "re-apropiarse" de La Trochita como recurso y la obtención de los beneficios que de ella se desprenden. Así crearon la Feria Tokom Topayiñ (en lengua mapuche significa Juntos Podemos), acondicionando una de las casas ubicadas en la estación de Tren, en la cual ofrecen diferentes productos y servicios, entre los que se destacan el lawen (hierbas medicinales) dulces, licores, ñaco, y trapi chazi (sales mapuches), bebidas, tortas fritas, roscas, guindados, suvenires, entre otros. Como parte de este proyecto, con el tiempo se fueron armando diferentes emprendimientos familiares como son: el proyecto de gastronomía originaria "Sabor Mapuche"; el proyecto de Producción de Hierbas medicinales "Ruka Antu Huilen"; el proyecto de Construcción de espacio de dormis y camping "Ruka Maykono"; el proyecto de cabalgatas y visitas guiadas por el territorio "Epu Peñi".

Los entrevistados destacaron que si bien estos proyectos de turismo rural comunitario son incipientes es llamativo que desde el Municipio no se lo promueve ni difunde, no aparece en la folletería oficial y no es parte del relato de los guías del viaje de la Trochita ni de la página web del municipio. Sin embardo, en las entrevistas realizadas a varios de los miembros de este proyecto han señalado que para ellos es una oportunidad para "salir del lugar pasivo" que venían teniendo en la visita turística de la Trochita a la estación de Nahuelpan y así poder desarrollar una estrategia turística comunitaria. En palabras de uno de los asesores turísticos --que si bien no es miembro de la comunidad trabaja en conjunto con las familias mapuche-- el principal objetivo de este proyecto es "abrir la comunidad al turismo" y que logren algún beneficio económico que "permita complementar la cría de animales"(J. P. Entrevista personal, 2017). Otros miembros de la comunidad plantearon que ellos piensan este proyecto turístico como una oportunidad para "hacer visible la comunidad" y así, "mostrar lo que la comunidad hace todos los días en el territorio".

Pero aunque este tipo de turismo puede resultar beneficioso para las economías locales, su introducción no está exenta de conflictos. En esta línea, Jordi Gascón (2011) plantea que el turismo --como cualquier otra actividad que genere beneficios-- aparece como un espacio de conflicto social, tanto en la aplicación de los recursos y como en la distribución de los beneficios que de este se obtienen. Desde esta lógica, se produce una reconfiguración del territorio sino también de las actividades productivas que tienen cabida en él, a partir de un nuevo proceso de valoración de sus cualidades físicas como simbólicas. Como parte de ésto, el territorio se vuelve un medio en el cual se expresan múltiples procesos - ambientales, económicos, políticos, históricos y culturales - que se manifiestan en los sentidos de pertenencia y adhesión que un grupo o comunidad puede expresar hacia ciertos lugares como espacios de elaboración y re-elaboración de identidades. Alicia Barabás (2004) se refiere a estos territorios como "etnoterritorios", entendiéndolos como el territorio histórico, cultural e identitario que cada grupo (etnia) reconoce como propio, ya que en él no sólo encuentra morada, sustento y reproducción como grupo, sino que también encuentran en ese espacio, la oportunidad de reproducir su cultura y prácticas sociales a través del tiempo. En palabras de la autora: "los etnoterritorios pueden comenzar a entenderse a partir de la singular conjunción de las categorías de tiempo, espacio y sociedad que se concretan en la historia de un pueblo en un Lugar" (Barabás, 2010: 12). Como se vió a lo largo del trabajo, las personas entrevistadas conciben el desarrollo de los proyectos de turismo comunitario no solo desde la lógica mercantil, como una oportunidad de obtener un beneficio económico, sino que lo conciben como una forma de arraigo, que les permite garantizar su permanencia territorial y cultural en ese lugar.

\section{Reflexiones finales}

A lo largo de estas páginas, se analizó cómo a través de la narrativa histórica oficial se estructuran geografías hegemónicas que determinan los espacios y los circuitos dentro de los cuales las personas deben llevar a cabo su movilidad (Grossberg, 1992). A su vez, a través del análisis del proceso de turistificación ${ }^{7}$ de la Estación de tren Nahuelpan se mostró cómo a través del discurso turístico también se delimitan espacios y se construyen sentidos e imaginarios sociales sobre la alteridad indígena.

Las narrativas oficiales y turísticas realizan una escenificación sobre "lo mapuche" que construye una imagen escencializada, folklorizada y localizada. Las construcciones estereotipadas e instituídas de los sujetos indígenas son ahistóricas, se encuentran asociadas a un pasado y se las piensa de manera fija en el espacio e intacta a través del tiempo. Como observamos a lo largo del trabajo, los relatos oficiales no hablan de conflicto ni de transformación, se refieren a la comunidad mapuche como un producto cultural escaso y "vestigio de un pasado". El relato oficial se conforma a partir de mecanismos como el 
silenciamiento y el borramiento, no solo de las memorias, sino también de los proyectos y actividades que la comunidad emprende. De esta manera, el relato oficial no incluye las memorias familiares sobre el poblamiento de la zona ni la historia de sometimiento y expropiación del desalojo, como tampoco menciona las luchas por el territorio que llevan adelante estos grupos desde hace años.

La patrimonialización de la Trochita, y el paseo turístico a la Estación Nahuelpan, se enmarca en un contexto de exclusión previamente existente, que se ha visto reforzado por medio de las transformaciones territoriales que acarrea el turismo. En este sentido, el análisis sobre cómo se configura la trama de poder en el territorio nos ha permitido repensar las modalidades en que el Estado construye narrativas, regula y delimita el espacio. Así como también, las múltiples maneras en que esas configuraciones territoriales son, al menos, cuestionadas y puestas en tensión por la misma comunidad.

Como se vió a lo largo del trabajo, el desarrollo de las experiencias de turismo rural comunitario --que en los últimos años algunas familias han encarado con mucho esfuerzo-- constituyó para estos grupos una forma de "permanencia" en el territorio. A través de estos proyectos, pretenden no solo re-significar la llegada del turismo con "la Trochita", sino también encontrar un espacio donde contar su propia historia y obtener, más allá del aporte económico, un espacio de disputa donde negociar sus propios "sentidos de lugar".

\section{Bibliografía}

Barabás, Alicia 2004. "La construcción de etnoterritorios en las culturas indígenas de Oaxaca". En: Desacatos, No. 14, México.

2010 El Pensamiento Sobre El Territorio En Las Culturas Indígenas De México. Avá Revista de Antropología. 17: 11-22.

Crespo, Carolina 2017. Contornos de lo decible, exhibible y pensable. Los pueblos originarios en las políticas turístico-culturales en el noroestede de Chubut (Patagonia, Argentina). Revista Pasos. Vol. 15 N. 3. 533-544.

De Vera, Gustavo. 1999. "Memoria del Humo" Historias de vida en Lago Rosario, Municipalidad de Trevelin.

Delrio, Walter. 2005. "Etnogénesis, hegemonía y nación. Construcción de identidades en Norpatagonia", 1880-1930. Bernal: Universidad Nacional de Quilmes.

Díaz, Chele. 2003. 1937: el desalojo de la tribu Nahuelpan. Editorial Musiquel, El Bolsón

Didi-Huberman, Georges. 2014. Pueblos expuestos, pueblos figurantes. Buenos Aires: Editorial Manantial.

Dwyer, Leslie. Leslie. 2009. "A politics of Silences: Violence, Memory and Treacherous Speech in Pos-1965 Bali”. En A. O' Neil y K. Hinton (Eds.) Genocide, Truth, Memory anda Representation, Durhan y London: Duke Universuty Press. Pp. 113-146.

Fiori, Ayelen. 2019. "Las taperas hacen que no podamos olvidar el desalojo" Memorias de expropiación territorial en Boquete Nahuelpan. Revista Runa, 40 (1), 101-112

García Canclini, Nestor. 1989. “Quiénes usan el patrimonio?. Políticas culturales y participación social», en Antropología, México, Boletín oficial del INAH, nueva época, núm. 15- 16, julio-octubre, 11-24.

Gascón, Jordi. 2011. Turismo rural comunitario y diferenciación campesina. Consideraciones a partir de un caso andino [En línea]. Mundo Agrario, 11(22). Disponible en Memoria Académica: http://www. memoria.fahce.unlp.edu.ar/art_revistas/pr.4785/pr.4785.pdf

Gimenez, Gilberto. 2002. La cultura como identidad y la identidad como cultura, UNAM, México.

Grossberg Lawrence. 1992. We gotta get out of this place. Popular conservatism and postmodern culture. New York: Routledge.

Haesbaert, Rogéiro. 2013. "Del mito de la desterritorialización a la multiterritorialidad". Rev. Cultura $y$ representaciones sociales. Año $8 \mathrm{~N}^{\circ} 15$. México.

Ingold, Tim. 2011. Essays on movement, knowledge and description, New York: Routledge.

Lenton, Diana. 2014. "De centauros a protegidos. La construcción del sujeto de la política indigenista argentina a través de los debates parlamentarios". Corpus. Archivos virtuales de la alteridad americana 4 (2).

Mases, Enrique. 2002. Estado y Cuestión indígena: el destino final de los indios sometidos en el sur del territorio argentino (1878-1910), Bs.As. Prometeo.

Minieri, Ramon. 2006. Ese ajeno sur. Viedma: Fondo Editorial Rionegrino.

Oriola, Jorge. 2014. "Esquel. Poder, prácticas y discursos“ (1890-1945) Remitente Patagonia.

2004 Esquel, del telégrafo al pavimento. Esquel: UHF Patagonia. 
Prats, Llorenç. 1997. Antropología y Patrimonio, Ariel, Barcelona.

Prats, Llorenç y Santana, Agustín. 2011 "Turismo, identidad y patrimonio, las reglas del juego. Pasos, 5: Turismo y Patrimonio entramados

narrativos: 1-12.

Ramos, Ana y Briones Claudia. 2016. "Andábamos por todos lados como maleta de loco": impactos de un desalojo sobre las memorias y prácticas de la comunidad del Boquete Nahuelpan, noroeste de Chubut. En: Parentesco y Política. Universidad Nacional de Rio Negro.

Ramos, Ana y Delrio, Walter. 2005. "Trayectorias de oposición. Los mapuches y tehuelches frente a la hegemonía en Chubut", en Briones, Claudia Cartografías Argentinas. Políticas indigenistas y formaciones provinciales de alteridad, Buenos Aires, Antropofagia.

Ramos, Ana. 2010. Los pliegues del linaje. Memorias y políticas mapuches-tehuelches en contextos de desplazamiento, Bs. As, Eudeba.

Sourroullie, Marcos. 2018. Nahuelpan, Colonia 16 de Octubre y Argentine Southern Land Co. La colonización del territorio nacional del Chubut (1885-1937) Tesis de Doctorado. Facultad de Filosofía y Letras. Universidad de Buenos Aires.

Tilley, Christopher. 2006. "Introduction: Identity, Place, Landscape and Heritage". Journal of Material Culture, 11(1/2): 7-32

Troiano, Marcelo. 1993. "Y nació Esquel" Esquel: el autor.

Trouillot, Marcelo. 1995. Silencing the Past: Power and de Production of History, Boston: Beacon Press.

\section{Fuentes utilizadas:}

Folletería Tokom Topayiñ Grupo de Turismo Rural comunitario Lof Nahuelpan.

Número Especial del Diario Esquel en sus Bodas de Plata. Esquel, 1950

Sitio Oficial de la Dirección de Turismo de la Municipalidad de Esquel: http://www.esquel.tur.ar/disfruta/ excursiones-aventura/pueblos-originarios

Sitio Oficial de La Trochita: http://latrochita.org.ar/

Sitio Web: www.patagonia.com.ar

\section{Notas}

1 Este trabajo es una versión ampliada y revisada de la ponencia presentada en las IX Jornadas de Investigación en Antropología Social "Santiago Wallace" (Facultad de Filosofía y Letras, Universidad Nacional de Buenos Aires, noviembre de 2018, Buenos Aires, Argentina) como parte de la investigación en curso para mi tesis doctoral.

2 La historia de Boquete Nahuelpan ha sido abordada recientemente por algunos historiadores y antropólogos, quienes se fueron centrando en la concesión de tierras de 1908 y los primeros años de conformación de la reserva (Sourroullie, 2019); en el desmantelamiento de la misma en 1937 (Díaz, C. 2003; Delrio, 2005; Lenton 2014) y en las memorias sobre la dispersión después del desalojo (Briones y Ramos, 2016; Fiori, 2019)

3 "El decreto $\mathrm{N}^{\circ} 105.137$ del 5/5/1937, firmado por Justo, deja sin efecto un decreto del presidente Figueroa Alcorta del 3/7/1908 (...) en el que se establecía la localización de los terrenos y reservas, respectivamente, para "la agrupación indígena de Francisco Nahuelpan", en el área reservada para la ampliación de la Colonia 16 de Octubre, en el territorio nacional del Chubut" (Lenton, 2014: 348).

Edición Especial por el 25 Aniversario del Diario Esquel (1950)

Extraído del sitio web: http://www.esquel.tur.ar/disfruta/excursiones-aventura/pueblos-originarios

Extraído del sitio web: http://www.patagonia.com.ar

Entendemos "turistificación" como el proceso por el cual se transforma un hecho histórico, social o cultural en un producto valioso para el mercado turístico. 